\title{
Hinges and Certainty. A Précis of Moore and Wittgenstein. Scepticism, Certainty and Common Sense
}

\author{
Annalisa Coliva
}

Received: 22 July 2012 / Accepted: 13 September 2012 /

Published online: 23 October 2012

(C) Springer Science+Business Media Dordrecht 2012

In a perplexing passage of On Certainty (Wittgenstein 1969) Wittgenstein writes:

Haven't I gone wrong and isn't Moore perfectly right? Haven't I made the elementary mistake of confusing one's thoughts with one's knowledge? Of course I don't think to myself "The earth has already existed for some time before my birth", but do I know it nevertheless? Don't I show that I know it by always drawing its consequences? (OC 397)

Is Wittgenstein really retracting his criticism of the Moorean use of "to know" and conceding that, after all, we do know that the Earth has existed for a very long time, and other "hinges", as these propositions have become known in the literature? In my Moore and Wittgenstein. Scepticism, Certainty and Common Sense (Coliva 2010), I have argued that this isn't the case. In this précis, while maintaining that view, I would like to insist more than I have done before on the characteristic duplicity of hinges - i.e. their retaining a descriptive content, while playing a normative function.

In the book I have contended that, with respect to the role of hinges, Wittgenstein held the view that we don't bear to them a genuinely epistemic relation, such that one could meaningfully claim to know them. I have also pointed out that he becomes more and more wary of describing that relation in other ways, e.g. as "assuming", "believing" or "being certain". For all verbs of propositional attitude suggest the idea that we may believe hinges because we have evidence for them, or that we assume them, but they may turn out to be false; or else, finally, that our certainty with respect to them is of a

Previous versions of this précis have been delivered at a workshop at Hatfield in the Fall 2011, at a seminar in Edinburgh in the Spring 2012 and at the European Epistemology Network Meeting in Bologna and Modena in the Summer 2012. I would like to thank Danièle Moyal-Sharrock, Britt Harrison, Duncan Pritchard, Allan Hazlett, Chris Kelp, Claudine Tiercelin and all people in attendance at these events for their challenging and useful comments.

\footnotetext{
A. Coliva $(\bowtie)$

University of Modena and Reggio Emilia and COGITO, Via Università, 4, 41100 Modena, Italy

e-mail: annalisa.coliva@unimore.it
} 
psychological nature and a function of the fact that we find it psychologically impossible to call them into doubt. By contrast, I have claimed that, according to Wittgenstein, it is precisely the idea that hinges could be semantically assessed by means of a method of comparing them with reality that is deeply misleading. For they themselves determine the method(s) by means of which we can establish whether ordinary empirical propositions are true or false (OC 151).

Perhaps at the cost of some generalization, it can be maintained that since at least Armengaud's (1983), up to Moyal-Sharrock's reading (2005), through a number of other interpretations such as Wolgast's (1987) and Stroll's (1994), it has been felt as a potential problem (Wolgast, Stroll, Moyal-Sharrock), ${ }^{1}$ or even a paradox (Armengaud) that certainties should lose their status as soon as they are spoken and that we may find it impossible to express the relationship we bear to them. In this précis, I will develop the suggestion, already contained in my book, that much of the puzzlement disappears if one keeps in mind that hinges can be said as such at least when we may need to teach or remind ourselves or others of their role and that we can perfectly well preface them with "I know", provided that expression is meant as a grammatical remark, and not as an expression of a genuinely epistemic relation.

\section{"I know", "I know”, “I know"}

In chapter two of Moore and Wittgenstein, I have claimed that in OC three different uses of "I know" are considered. ${ }^{2}$ First, there is the empirical use of "I know", i.e. the use one would make if one said "I know there are about half million people in this town". The characteristic features of such a use of "I know" are: (i) its being based on reasons; (ii) which are stronger than what they are supposed to ground, so as to remove possible agnosticism with respect to what is said to be known; (iii) it must be possible to make an inquiry to verify that things are as one claims to know them; (iv) it must make sense to say that one doesn't know what one in fact claims to know; and, finally, (v) the claim to knowledge must be relevant. Notice that this last constraint isn't at all equivalent to Grice's conversational maxim - it isn't merely pragmatic in nature -, rather, it has a semantic significance. For if a claim to knowledge (or any other claim) were made in irrelevant circumstances, in which it would be impossible to provide a reason for its making, it would become dubious that it has a meaning at all.

The second use of "I know" Wittgenstein draws attention to is grammatical. It was first introduced in the Philosophical Investigations (Wittgenstein 1953) in relation to self-ascriptions of mental states. As is well-known, for Wittgenstein there was no substantial inner epistemology and "I know I have a headache" could only be interpreted as meaning that, in these circumstances, the possibility of doubt would be removed, given the constitutive features of the language game at issue. Similarly,

\footnotetext{
${ }^{1}$ Yet they think Wittgenstein's position is ultimately consistent, although they account for it in different ways.

${ }^{2}$ In that chapter the reader will find a discussion of the relevant passages concerning each of these uses.
} 
when hinges are at stake, they could be prefaced by "I know" meant only in this grammatical sense. Here are the main features of such a use: (i) it doesn't express an epistemic relation between a subject and a proposition; (ii) so, a fortiori, it doesn't express knowledge, notwithstanding appearances to the contrary ${ }^{3}$; (iii) it isn't based on grounds, as these would either be identical to what one is claiming to know, like in the case of the self-ascription of a mental state, or less certain than what they would be supposed to ground, like in the case of hinges; (iv) its negation wouldn't make sense - i.e. it would be nonsense to say "I don't know I have a headache" or "I don't know that the Earth has existed for a very long time"; (v) it could be replaced by more perspicuous twists of phrase, such as "Here I can't be wrong", "Here a mistake or a doubt is (logically) impossible", "It stands fast for me, as well as for many others", or even "I couldn't admit any experience as proof to the contrary". 4

Finally, there is the philosophical or, better, the dogmatic use of "I know", which, according to Wittgenstein is the one either a Cartesian theorist with respect to the mental, or G. E. Moore with respect to hinges, would make if they were to say "Of course (only) I know what I am feeling" or "I know the Earth has existed for a very long time". The trouble would be to mean these claims as deep philosophical truths, which could be used to counter either a skeptic about self-knowledge (or at least about its being privileged with respect to other forms of knowledge) or else a skeptic about the long existence of the Earth. The salient characteristics of such a use of "I know" are: (i) the fact that it doesn't respect the criteria for the empirical use of "I know"; (ii) it couldn't be replaced by more perspicuous twists of phrase (preserving the meaning that either the Cartesian theorist or Moore would ascribe to it), as it isn't a grammatical use of "I know"; (iii) given (i) and (ii), it would literally be nonsensical; (iv) it retains an appearance of sense simply because we project it onto it from the contexts in which "I know" is used empirically. ${ }^{5}$

To sum up, underneath the superficial similarity, not all utterances of "I know" are on a par. Some express an empirical claim, and therefore make a genuine knowledge attribution, and, because of that, are meaningful; some others don't express an empirical claim, as they don't make a genuine knowledge ascription, but express a grammatical point. Yet, although they fail at bipolarity, they aren't sheer nonsense. Finally, some other utterances of "I know" are squarely nonsensical, as they wouldn't be either empirical or grammatical, but philosophical or dogmatic.

\footnotetext{
${ }^{3}$ Contrary to what Morawetz 1978, 2005; Pritchard 2005, 2011 and Williams 2004a, b, 2005 maintain.

${ }^{4}$ I personally think that Wittgenstein would condone such a grammatical use since he himself does make it throughout OC (and PI, for that matter). Be that as it may, the important point, which even someone who isn't persuaded by this last claim should grant, is that Wittgenstein is drawing the attention to the grammatical use of "I know" in OC (and even in some passages of PI). I am grateful to Danièle MoyalSharrock for pointing out this problem, although we ultimately disagree about the interpretation of Wittgenstein's position.

${ }^{5}$ One could claim that the dogmatic use of "I know" is simply a grammatical use unbeknownst to the user. I think, rather, that Wittgenstein is drawing the attention to the fact that philosophers are often misled and take their use of "I know" to be "metaphysical" - i.e. such as to express a truth that can't be denied - when in fact they are simply bumping against grammatical propositions. The "metaphysical" twist leads to nonsense; while seeing grammatical propositions for what they are (and stating that they are) isn't. Indeed it's the most - or even the best - a philosopher could do. I am grateful to Danièle Moyal-Sharrock for raising this issue, although we ultimately disagree about it.
} 


\section{Hinges}

In chapter four of Moore and Wittgenstein, I have claimed that the fact that one couldn't be wrong about certain propositions, signaled by the grammatical use of "I know" with respect to them, doesn't depend on one's privileged epistemic position, according to Wittgenstein. Rather, it depends on the role they play with respect to our language games and epistemic practices at large. ${ }^{6}$ For instance, "I know I have a headache" can't be called into doubt, if I am being sincere, not because I am acquainted with my headache in a way others couldn't be and because I "know it better" than anyone else. Rather, its immunity from doubt is a function of the role that statement plays with respect to our language game of self-ascribing sensations. In particular, it is a constitutive feature of such a practice that we accord authority over their own mental states to our interlocutors, bar special conditions such as slips of the tongue, insincerity and self-deception. The reason why we do so is not due to superficiality or hastiness but to the fact that any independent means we could set up to determine whether subjects are experiencing the sensations they are avowing would need, in order to be calibrated, to rely on subjects' own pronouncements. For instance, in order to set up a pain-detecting machine, we would need to individuate a brain state which were correlated to being in pain. But in order to determine whether a given neurological firing led to a painful sensation we would have to rely on subjects' own reports. ${ }^{7}$

Similarly, "The Earth has existed for a very long time" and the corresponding grammatical claim "I know the Earth has existed for a very long time" aren't based on one's privileged epistemic position $v i s-\grave{a}$-vis the long existence of the Earth. Nor is the matter certain and beyond doubt because we have conclusively ascertained its truth. Rather, its being beyond doubt is a constitutive feature of our practice of going about acquiring evidence in favor of specific attributions regarding the actual age of the Earth. Were we to give that hinge up, then no matter what kind of evidence we thought we had collected in favor of this or that specific age-attribution, it would simply lose its status of evidence, as its existence would then be compatible with its having been created just a short time ago.

So, there are propositions which, as we have seen, play a normative role with respect to some of our language games and epistemic practices. This doesn't mean that they are formulated as explicit rules, such as "Do $\varphi$ ", or "If C, $\varphi$ ". Yet, even if they are, or can be the content of a judgment, they play a normative role, like "Patience is played alone". Using Wittgenstein's metaphor: they are what must stay put, if we want "the door to turn", like hinges (OC 343).

It is useful to consider another example of what, in context, would be a hinge, for Wittgenstein, viz. "Here is my hand". Such a proposition could be used to explain or define the meaning of "hand" in English. But also, and more importantly, to determine what would count as normal conditions of perception and of human functioning. If it were possible to call into doubt that judgment, in the relevant context, one could

\footnotetext{
${ }^{6}$ In that chapter the reader will find a discussion of some key passages.

${ }^{7}$ Notice that the sensation of pain need not invariably correlate with precisely that firing. For instance, due to other factors, a subject could feel no pain, while having that neurological firing.
} 
no longer rely on one's perceptions and/or cognitive abilities, not even to gather evidence which could speak against it.

Now, some Wittgensteinian scholars, most notably Danièle Moyal-Sharrock in her seminal volume Understanding Wittgenstein's On Certainty, would refrain from calling hinges "propositions", and would rather call them "sentences" on the grounds that propositions would be defined by reference to their bipolarity - i.e. to the possibility of being both true and false. ${ }^{8}$ On their view, the normative role hinges are said to play precludes the possibility of their being propositions, for they wouldn't be semantically assessable. After all, it doesn't make sense to semantically evaluate "Patience is played alone" or "Stop at the traffic light, when red". When no semantic evaluation is possible, then talk of a proposition would be out of place. ${ }^{9}$ Yet the non propositional reading comes at significant theoretical costs. First and foremost, the fact that we seem perfectly able to entertain hinges in thought, and let them play the role of suppositions, in order to consider, for instance, what does follow from them e.g. "If the Earth has been existing for a very long time, oceans have too" - in ways which would be precluded if they weren't propositions. ${ }^{10}$

It has to be noticed, however, that by the time of OC, the term "proposition" (Satz) had come to express a fairly relaxed notion in Wittgenstein's writings. In OC 320, for instance, he writes that one must "remember that the concept 'proposition' itself is not a sharp one". Surely, (purely) empirical propositions are still characterized by bipolarity. But this doesn't mean that only (purely) empirical propositions are propositions, for Wittgenstein. So, also linguistic items endowed with a use and hence a meaning, but failing at bipolarity could rightly be regarded as propositions. Their function wouldn't, clearly, be descriptive, yet they could be used to do many other

\footnotetext{
${ }^{8}$ It is an open issue whether they should object to the idea, which is suggested in some passages of OC, that hinges could be used as paradigms of truth, in context. For, that would preclude their being false, in context, and hence would make them fail at bipolarity, as judging them false, at least in the relevant context, would be nonsensical. Of course they may want to insist that hinges can't be true either (OC 204). I think the relevant point here is that if, in context, they are paradigms of truth, and hence true, that doesn't make their role empirical, precisely because they couldn't sensibly be judged to be false. Moreover, they wouldn't be subject to verification and control; nor would they be held true because and after such an inquiry. Their being true, therefore, wouldn't depend on there being evidence in favor of them and, thus, they wouldn't be true in the same sense in which, for Wittgenstein, genuinely empirical propositions can be true, viz. when evidence speaks in favor of them. I think this is an extremely subtle issue, one for which OC doesn't provide a clear-cut view. For what is worth, there are passages in OC $(80-83,193,206)$ which suggest the idea that for Wittgenstein hinges are minimally true (cf. Williams 2004b). It remains, however, that several other ones suggest the idea that for Wittgenstein truth is epistemically constrained. Therefore hinges couldn't be either true or false (OC 162-3, 204-205, 222, 404, 500). In a conciliatory spirit one may thus put forward the idea that while for Wittgenstein hinges aren't true in this latter sense, they are true in the former, minimal sense. But, to stress, the issue is extremely subtle and difficult to adjudicate.

${ }^{9}$ For instance, in The Remarks on the Foundations of Mathematics (Wittgenstein 1967), (123) Wittgenstein suggests that since "propositions of logic are so constructed as to have no application as information in practice (...), it could very well be said that they were not propositions at all". I would like to thank Danièle Moyal-Sharrock for pointing out to me this interesting passage. However, two observations are in place: first, that the Remarks are a much earlier text and there is no reason to suppose that OC should comply with everything in it (cf. OC 320). Secondly, and more importantly, that Wittgenstein is here talking about propositions of logic, such as, I assume, tautologies, and not of hinges. While in OC their role is likened in some respects, this doesn't imply that they are exactly on a par and, in particular, it doesn't entail that hinges should be devoid of any informational content whatsoever.

${ }^{10}$ Pritchard 2012.
} 
things, such as to state norms, rather than facts; or else to pray, express wishes, hopes, intentions and so forth.

Indeed, at least since the discussion of family-resemblance concepts in PI 65-71, which is only superficially just about the concept of game, but which is in fact concerned with discarding the idea that had had a key role in the Tractatus, viz. that there could be something like the essence of language and the general form of the proposition (cf. PI 65, 89-108), Wittgenstein had already abandoned a unitary view of propositions. What we regard as propositions need not share a common essence, such as their bipolarity, but just a complicated network of family resemblances.

So, to sum up, by the time of OC, "proposition" was something of an umbrella term - a genus with many species, such as (purely) empirical propositions, characterized by bipolarity and serving merely a descriptive function; grammatical propositions, failing at bipolarity, serving a normative function; and other kinds of propositions, equally failing at bipolarity and serving functions other than the descriptive or the normative ones.

This, however, would be almost just a terminological remark, unless something more substantial depended on it. For one could then say that while, for Wittgenstein, hinges aren't empirical propositions, they are propositions in the sense of being sentences with meaning, which play a normative function. Yet this would not, in the end, be substantially different from saying that they aren't propositions - as they fail at bipolarity - and are rather just sentences that express a norm or a rule.

However, there are passages in $\mathrm{OC}$ which suggest a much more contentious idea particularly the ones around OC 95-99. For Wittgenstein there seems to be saying that a sentence, which is used to express an empirical proposition, is actually removed from doubt, in context, and thus has a normative role as well. The "channels" and "riverbed" - these are the metaphors Wittgenstein uses in those key passages - are in fact said to be made of empirical propositions, which have been hardened into rules. Hinges, on this view, seem to be Janus-faced. While their actual role is normative, they remain propositions with empirical import, as they convey a certain description of reality, which is not (any longer) subject to verification and control, yet is a description all the same. "The Earth has existed for a very long time", or "Here's my hand", "My name is AC", "Nobody has ever been on the Moon", are all cases in point. And there are circumstances - either synchronically or diachronically - which, at least in some cases, could demote these propositions from their rule-like role to let them play their (perhaps original) merely descriptive function. For instance, I could wake up from a car accident and find out, with relief, that here is my hand again; or else, technological progress could - as has happened - actually turn "Nobody has ever been on the Moon" into a falsehood, despite having been a hinge for ages. Finally, although the circumstances which could convert "The Earth has existed for a long time" into a merely empirical proposition are far-fetched, its apparent necessity is only a by-product of our world-picture, for Wittgenstein.

We therefore face a multiplicity of views, regarding hinges. According to a first reading, the same string of graphemes could express either an empirical proposition, or a rule or nothing at all. As a consequence, the same sentence - a string of graphemes belonging to some natural language - could express either an empirical proposition, or a rule. But it is equally a consequence of holding that meaning is use that the very same proposition (OC 98) could still be a description yet play, in 
context, a normative role. Obviously the first and the second option would be compatible with the view that rules - and hinges, in particular - aren't propositions, although they do not entail it; while the third wouldn't be compatible with such a view. In particular, it has to be stressed that the import of this third reading is that the very same proposition could play either a merely empirical role, or actually, while retaining its descriptive content, a normative one. This doesn't mean that one can no longer draw the distinction (OC 98). For one can draw the distinction at the level of function or role, rather than at the level of content, by taking into account the actual use of the proposition at issue, and by considering whether it is exempt from doubt. What it means, rather, is that hinges are propositions, which tell us something about objects and states of affairs (OC 401-2), while not being subject to the same kind of verification and control ordinary empirical propositions are subject to. So, despite their descriptive content, their role and function is, or has become similar to that of a norm or a rule. Wittgenstein calls it a "rule-like" function (OC 95).

I actually think that in OC there are passages which could support each of these views. Yet, these three readings would somehow be compatible if we took seriously the idea that meaning is use. To reiterate, it is use that determines whether a string of graphemes is meaningful, and hence a sentence of a natural language. It is again use that establishes whether that sentence expresses an empirical proposition or a rule. Finally, it is use that determines whether a given proposition, with its descriptive content, is actually removed from doubt, in context, and thus plays a normative role with respect to our epistemic practices.

\section{Certainty and Wittgenstein's Anti-Skepticism}

In the second and the fourth chapter of Moore and Wittgenstein, I have argued that certainty isn't either an epistemic category in OC, or a psychological one. ${ }^{11}$ The non propositional reading of hinges has often been coupled with the idea that, properly speaking, certainty is a non propositional, non conceptual attitude that shows itself merely in action. The most developed account of this idea can be found in MoyalSharrock's Understanding Wittgenstein's On Certainty.

Surely "animal certainty" - as this view is often labeled - is a theme in OC, but I don't think it is the focus of the book, or its most original contribution to the debate about the relationship between skepticism and common sense. The focus of On Certainty, notwithstanding the deceptive appearance suggested by the title, ${ }^{12}$ are hinges and the characterization of their role within our epistemic practices. Using a helpful terminology introduced by Moyal-Sharrock, we could say that at the heart of OC lie "certainties" rather than certainty itself, i.e. the contents rather than the attitude. Nor would "animal certainty" be a substantially new and potentially successful idea to be used within an anti-skeptical strategy. After all, Hume himself recognized that we act with a certainty that knows no doubt in our everyday lives and that we couldn't but act that way. Yet, this would by no means come as a relief vis-àvis skeptical preoccupations. For a skeptic is actually asking for a justification of the

\footnotetext{
${ }^{11}$ In those chapters the reader will find a discussion of the relevant passages.

${ }^{12}$ As is well-known, the title was given by the editors.
} 
propositions, which are the contents of our most deep-seated beliefs and this is what "animal certainty" wouldn't deliver, precisely because it would ultimately reduce them to mere ways of acting. Rather, by a skeptic's lights, "animal certainty" is what we have to be content with, once we realize, with him, that no justification for them is attainable. So, a proper anti-skeptical strategy has to confront the challenge of showing either that these propositions are after all justified, or else that, even if they aren't, they aren't merely arbitrary assumptions. We will briefly look at OC's antiskeptical import in a moment. For now, let me dwell a bit more on what I take OC's message about certainty to be. ${ }^{13}$

As a matter of fact, certainty in OC comes down to a propositional and therefore conceptual attitude of acceptance, which displays itself mostly in action but that doesn't show itself only in action. Furthermore, it requires some conceptual repertoire on a subject's part, so as to enable her to entertain, if necessary, its contents. In particular, acceptance is a genus that comes in two species. One, which we could call "epistemic acceptance", ${ }^{14}$ has as contents empirical propositions and differs from belief because these empirical propositions are held with no warrant. For instance, one could assume (epistemically) that Pisces are sensitive, or that black cats bring bad luck. But one could also assume that the butler is the culprit, having no evidence for it (whether or not one will eventually be able to collect that evidence). Another species of acceptance is what we might call "pragmatic acceptance" and has norms as content. For instance, most people accept to stop at traffic lights when red; or to say "sorry" when they step onto someone else's foot on the street. These are all norms and their acceptance is most often tacit (or even implicit) and shown in behavior that conforms to the norm. ${ }^{15}$ Yet, in a Wittgensteinian perspective, it can only be attributed to creatures who can somehow grasp its content. For it doesn't make sense to say that a 1-year old child, say, accepts to stop at a traffic light - viz. that she accepts that norm - if she has no idea of what a traffic light is, of what its being red means, etc. So, even if, as a matter of coincidence, she did stop at a red traffic light, that couldn't be taken as a sign of a tacit (or implicit) acceptance of the norm. Now, pointing out that we have been trained to act that way would show the genealogy (or the etiology) of both our eventual acceptance and of the fact that we would recognize its content as a norm (or, mutatis mutandis, as a hinge). But it wouldn't be enough either to turn the kind of certainty Wittgenstein is mostly concerned with in OC into merely "animal" certainty or to make it necessarily non-propositional and non-conceptual. To reiterate: the training may well be the cause of our behavior but it is only when we can somehow grasp the content of the norms we abide by that we can be said to accept them and that they can play the role of certainties for which it makes no sense to raise doubts.

Let us now briefly turn to the issue of OC's anti-skeptical import. ${ }^{16}$ As said, I don't think it lies in reminding us that we do in fact act with no doubt, since this would be

\footnotetext{
${ }^{13}$ Cf. chapter 4 of Moore and Wittgenstein.

${ }^{14}$ Such a kind of acceptance isn't what Wittgenstein is concerned with in OC. Cf. OC 343, 411, although he himself characterizes our attitude with respect to hinges in terms of acceptance (Cf. OC 344), which is mostly tacit (or even implicit) and manifests itself in action.

${ }^{15}$ So, there is very little need (if ever) to entertain its contents in mind before applying the relevant norms.

${ }^{16}$ Chapter 3 of Moore and Wittgenstein contains a much more developed discussion of Wittgenstein's antiskeptical strategies in OC. In particular, it contains an interpretation of Wittgenstein's arguments against the dreaming hypothesis, which I can’t take up in this précis.
} 
perfectly compatible with skepticism. I take it that the more interesting strategy against skepticism proposed in OC consists, rather, in deploying a certain analogy. Just as it would be a categorial mistake to call rules into doubt, similarly it is a categorial mistake to call into question those hinges that, while having a descriptive content, are hinges precisely because they play a rule-like role with respect to our epistemic practices.

Contrary to recent interpretations, ${ }^{17}$ I don't think Wittgenstein was tempted by the idea that certain merely descriptive propositions could enjoy something of a nonevidential warrant - an "entitlement" - which would make their acceptance epistemically secure. I don't think there is any evidence of that idea in OC, its intrinsic merits and interest notwithstanding. In fact, the passages on which that kind of reading is based have arguably been misunderstood. For in OC 341-344 Wittgenstein is saying that it belongs to the "logic" of our scientific investigations that certain things aren't doubted. The term "logic", however, in the later Wittgenstein's writings is safely replaceable by "grammar", meant in the extended sense of comprising both norms of linguistic and of evidential significance. Nowhere does the use of that term suggest the idea that Wittgenstein might mean a non evidential kind of warrant, i.e. an "entitlement" in Wright's terminology, which should attach to otherwise a-rational assumptions and turn them into epistemically rationally held ones. Furthermore, in OC 343 Wittgenstein is actually denying that, since we can't investigate everything, we must rest content with assumptions, for which we would possess, at most, a rational entitlement. So, the picture that emerges from these key passages is that there are propositions which play a normative role with respect to our scientific (but also more mundane, empirical) investigations. We can't call them into doubt, precisely because of their normative role and not because they are ungrounded assumptions we must rest content with if we want to pursue our investigations, or because they are made epistemically secure by some special kind of non-evidential warrant. To stress, the idea is, rather, that if an epistemic practice is made possible by holding fast certain propositions, whose function is normative, it doesn't make sense to raise doubts against them. For this would, at once, betray a misunderstanding of their status and would deprive one of the means to actually raise sensible - that is empirically grounded - doubts. For to raise that kind of doubt, those very hinges must be in place. This, I take it, is a novel and potentially fruitful idea which has at least the merit of being incompatible with skepticism and of providing a diagnosis of what is wrong with it.

One could object that to point out the normative role of hinges couldn't safeguard against skeptical assaults, because a skeptic could claim that we may actually have rules which aren't at all rationally defensible. I think this objection would be unfair to Wittgenstein's point. For he isn't talking just of any possible rule, but of those we bump into, as it were, when we investigate our scientific and mundane epistemic practices and discover their presuppositions. Namely, those propositions that are presupposed by all inquiry, at least in the area at issue. Now, if we also agree that the notion of epistemic rationality skeptics and non skeptics alike doesn't hang in the air, but actually depends on

\footnotetext{
$\overline{{ }^{17} \text { See Wright } 2004 \text { and Williams } 2004 a, \text { b. }}$
} 
those practices, it turns out that their hinges are actually constitutive of epistemic rationality itself and that's why they can't be doubted. ${ }^{18}$

Actually, in chapter three of the book, I have maintained that Wittgenstein also made the stronger claim that since skeptical doubts are unmotivated, for the reasons just sketched, they are actually not meaningful. They are pieces of nonsense which, however, retain an appearance of sense because we project it onto them from ordinary contexts of doubt. Now, I think, as I have stressed in the book, that this claim is much more contentious and difficult to defend, in my view, and for this reason less fruitful. Yet, it is undoubtedly another avenue of potential development for an anti-skeptical strategy; one which would require one to be prepared to embrace a strong version of the idea that meaning is use.

\section{Are Hinges qua Hinges Effable?}

According to the non propositional reading, hinges, as such, aren't sayable. The idea behind the non propositional reading is that, properly speaking, only what meets the requirement of bipolarity and is therefore a proposition, can actually be said. ${ }^{19}$ What this means is that being sayable requires playing only a descriptive role ${ }^{20}$ and being a move within the language game. But hinges do not, nor can they play such a role, for they fail at bipolarity. Hence, they aren't propositional and descriptive, and can never be passed within the language game as a piece of information. If and when they are uttered, they are only spoken heuristically, to remind someone of their status and role. But this wouldn't amount to saying them and, as a matter of fact, hinges would manifest or show themselves as such only in action.

Now, as is well-known, the saying/showing dichotomy is a sort of "technical" distinction that belongs to the Tractatus. By the time of OC, through the development along the years of the notion of grammar and of grammatical proposition, I think it lost much of its importance and theoretical significance. After all, in the Tractatus, among the many things which couldn't be said but only shown, there were the conditions of sense. But later, they had become effable in the form of grammatical propositions. Indeed, much of Wittgenstein's positive contribution to philosophy, as he puts it in a suggestive image in the Philosophical Investigations, is to let us see that whole clouds of metaphysics are condensed in a drop of grammar (PI II, p. 222). To take that dichotomy seriously is what would force one to hold that hinges qua hinges are only shown in action. But Moyal-Sharrock herself - the chief holder of this view - wants hinges to be effable at least when they serve the heuristic purpose of

\footnotetext{
${ }^{18}$ In Chapter 4 of Moore and Wittgenstein I expound on this issue and contend that Wittgenstein shouldn't be regarded as an epistemic relativist. There are various reasons for that, but notice that the propositional reading of hinges allows for them to be demoted and to become ordinary empirical propositions which could then be false. Indeed there are passages which suggest that Wittgenstein would have allowed for "Nobody has ever been on the Moon" to be false, had evidence been assembled to prove that. In that case, however, it would no longer have been a hinge.

${ }^{19}$ Moyal-Sharrock allows also for "avowals" to be sayable (cf. her 2005, p. 45 and fn. 23). Be that as it may, the crucial aspect of this reading of OC is that hinges aren't (empirical) propositions and, for this very reason, can't be said.

${ }^{20}$ See previous footnote.
} 
reminding a philosopher of their proper role, or of teaching someone the rules that govern our linguistic and epistemic practices. Yet, when they are spoken in order to serve these latter purposes, they are actually presented as hinges and not as something else, I take it. So there is a tension here: either, whenever spoken, hinges aren't presented qua hinges, and they can manifest themselves as such only in action; or else, they can after all be said qua hinges, even though to serve merely heuristic purposes, as is actually the case when we do philosophy with Wittgenstein and engage in the more ordinary activity of teaching someone how (best) to take part in our linguistic and epistemic practices.

I claim, in keeping with what I have argued in the book, that the interpretation of hinges that makes sense of this latter possibility, which I think, with Moyal-Sharrock, is indisputable, is the propositional reading of hinges. For that interpretation helps us retain several crucial aspects. First, it allows us to maintain that hinges have a descriptive content and yet it allows us to focus on the normative role they play, in context. As we saw before, "The Earth has existed for a very long time" does provide a description of a state of affairs, yet it isn't like any other empirical proposition which is subject to verification and control. In this sense, it plays a different, normative role, yet it retains a descriptive content. Furthermore, the propositional reading, by deflating the idea that bipolarity is the mark of the propositional, allows us to retain the view that also norms can be propositions and, in particular, become the content of a propositional attitude of acceptance - the pragmatic acceptance we mentioned before $(\S 3)-$, which can perfectly well be expressed in speech and enter two absolutely legitimate language games. Namely the language game of teaching someone our linguistic norms and our norms of evidential significance; and the language game of doing proper philosophy with Wittgenstein, by reminding those who had gone astray of some grammatical facts. Although I am aware that this latter practice might not be considered a real language game by Wittgenstein's own lights and conception of philosophy, there is no doubt that in the later Wittgenstein the former would be a genuine language game. After all, the very idea of a language game is introduced in the Philosophical Investigations in connection with the conditions and preconditions for this kind of teaching (PI 7 and paragraphs around it). So, hinges are effable as such within some language games, though not in ones which serve a merely descriptive purpose. But isn't it the lesson of Wittgenstein's later philosophy that we shouldn't be fixated with just that use of language? And if that obsession is abandoned, then a number of only seemingly clear-cut distinctions, such as the propositionality/non-propositionality and the saying/showing dichotomy, would have to be discarded as well.

\section{References}

Armengaud, F. (1983). Moore et Wittgenstein: 'Je crois que'/‘Je sais que. In H. Parret (Ed.), On believing. Epistemological and semiotic approaches (pp. 31-47). Berlin-New York: V. de Gruyter.

Coliva, A. (2010). Moore and Wittgenstein. Scepticism, certainty and common sense. London: Palgrave. Morawetz, T. (1978). Wittgenstein and knowledge. The importance of On Certainty. Atlantic Highlands N. J: Humanities Press.

Morawetz, T. (2005). The contexts of knowing. In D. Moyal-Sharrock \& W. H. Brenner (Eds.), Readings of Wittgenstein's On Certainty (pp 165-88). London: Palgrave. 
Moyal-Sharrock, D. (2005). Understanding Wittgenstein's On Certainty. London: Palgrave.

Pritchard, D. (2005). Wittgenstein's On Certainty and contemporary anti-scepticism”, in Moyal-Sharrock, D., \& Brenner, W. H. 2005 (eds.), 189-224.

Pritchard, D. (2005). Wittgenstein's On Certainty and contemporary anti-scepticism. In D. Moyal-Sharrock \& W. H. Brenner (Eds.), Readings of Wittgenstein's On Certainty (pp 189-224). London: Palgrave.

Pritchard, D. (2011). Wittgenstein on scepticism. In O. Kuusela \& M. McGinn (Eds.), Oxford Handbook of Wittgenstein (pp. 523-549). Oxford: Oxford University Press.

Pritchard, D. (2012). Wittgenstein and the groundlessness of our believing, in Coliva, A., Morruzzi, S., \& Volpe, G. (eds.) Scepticism and Justification, special issue of Synthese, doi 10.1007/s11229-011-0057-8.

Stroll, A. (1994). Moore and Wittgenstein on Certainty. New York: Oxford University Press.

Williams, M. (2004a). Wittgenstein's refutation of idealism. In D. McManus (Ed.), Wittgenstein and scepticism (pp 76-96). London-New York: Routledge.

Williams, M. (2004b). Wittgenstein, truth and certainty. In M. Kölbel \& B. Weiss (Eds.), Wittgenstein's Lasting Significance (pp. 249-284). London-New York: Routledge.

Williams, M. (2005). Why Wittgenstein wasn't a foundationalist. In D. Moyal-Sharrock \& W. H. Brenner (Eds.), Readings of Wittgenstein's On Certainty (pp 47-58). London: Palgrave.

Wittgenstein, L. (1953). Philosophical investigations. Oxford: Blackwell.

Wittgenstein, L. (1967/1978). Remarks on the Foundations of Mathematics, Oxford, Blackwell.

Wittgenstein, L. (1969). On Certainty. Oxford: Blackwell.

Wolgast, E. (1987). Whether certainty is a form of life. The Philosophical Quarterly, 37, 161-165.

Wright, C. (2004). Wittgensteinian certainties. In D. McManus (Ed.), Wittgenstein and scepticism (pp 2255) London-New York: Routledge. 